\title{
Los volcanes: algunas perspectivas para un conocimiento científico y didáctico
}

\author{
F. Javier Perales-Palacios (D) \\ Departamento de Didáctica de las Ciencias Experimentales, Universidad de Granada, España. \\ fperales@ugr.es \\ Javier Carrillo-Rosúa iD \\ Departamento de Didáctica de las Ciencias Experimentales, Instituto Andaluz de Ciencias de la Tierra, \\ (CSIC-UGR). Universidad de Granada, España.fjcarril@ugr.es
}

\author{
Araceli García-Yeguas \\ Departamento de Didáctica de las Ciencias Experimentales, Instituto Andaluz de Geofísica. Universidad de \\ Granada,España.araceligy@ugr.es
}

Mercedes Vázquez-Vílchez

Departamento de Didáctica de las Ciencias Experimentales, Universidad de Granada, España. mmvazquez@ugr.es

[Recibido: 26 enero 2021. Revisado: 30 abril 2021. Aceptado: 11 mayo 2021.]

\begin{abstract}
Resumen: Los volcanes son uno de los contenidos más complejos de enseñar en educación obligatoria debido a la conjunción de las diversas dimensiones y variables que encierran. En este trabajo hemos analizado el concepto de volcán desde una perspectiva científica, didáctica y social. Para ello hemos establecido primero las dimensiones científicas que engloba el concepto de volcán. Respecto a la didáctica, hemos analizado y revisado el currículo de Educación Primaria y Secundaria, su tratamiento en libros de texto, las ideas previas de los estudiantes y las intervenciones educativas previamente publicadas. La dimensión social ha sido descrita teniendo en cuenta cómo aparecen los volcanes en la historia de la humanidad, medios audiovisuales, cine, literatura, arte y cuáles son sus beneficios y riesgos para la sociedad. Este trabajo pone de manifiesto que la temática de los volcanes presenta diversas implicaciones y oportunidades en el ámbito educativo que podrían enmarcarse dentro de enfoques como el de Ciencia-Tecnología-Sociedad (CTS).
\end{abstract}

Palabras clave: enseñanza de la geología; ciencias de la tierra; volcanes; conocimiento científico; conocimiento didáctico.

\section{Volcanoes: The basis for scientific and educational knowledge}

Abstract: Volcanoes are one of the most complex subjects to teach in compulsory education due to the combination of the various dimensions and variables they contain. In this work we have analysed concept of volcano from a scientific, didactic and social perspective. To do so, we have first established the scientific dimensions that the concept of the volcano encompasses. With respect to didactics, we have analysed and reviewed the Primary and Secondary Education curriculum, its treatment in textbooks, the previous ideas of the students and the previously published educational interventions. The social dimension has been described taking into account how volcanoes appear in the history of humanity, audiovisual media, cinema, literature, art, and what their benefits and risks for society are. This work shows that the topic of volcanoes presents deep implications and opportunities in the educational field that could be framed within approaches such ScienceTechnology-Society (STS).

Keywords: geology teaching; earth sciences; volcanoes; scientific knowledge; didactic knowledge.

Para citar este artículo: Perales-Palacios F. J., Carrillo F. J., García-Yeguas A. y Vázquez Vílchez M. (2021) Los volcanes: algunas perspectivas para un conocimiento científico y didáctico. Revista Eureka sobre Enseñanza y Divulgación de las Ciencias 18(3), 3105. doi: 10.25267/Rev_Eureka_ensen_divulg_cienc.2021.v18.i3.3105 


\section{Introducción}

El fenómeno de los volcanes representa una de las manifestaciones de la naturaleza más trágicas, espectaculares y sugerentes para la humanidad, habiendo sido motivo de múltiples acercamientos científicos, artísticos, espirituales, turísticos... en el transcurrir de la historia. Por otra parte, constituyen un testimonio vivo de las enormes fuerzas que rigen la dinámica interna de la Tierra, una terrible amenaza para las sociedades a la vez que un generador de recursos para las mismas. Junto con los terremotos, los volcanes representan un elemento cautivador para el aprendizaje de la Ciencias de la Tierra que los sistemas educativos no deberían desaprovechar.

A pesar de ese potencial, nos enfrentamos a un contenido complejo, con una conjunción de variables y dimensiones que lo hacen difícil de abordar en su integridad, al menos en los niveles obligatorios de la enseñanza. Aunque hay cada vez más observaciones síncronas de los procesos eruptivos, estos son solo la punta del iceberg; comúnmente su tratamiento se realiza a través de sus efectos, por lo que comprender los procesos que los provocan y favorecen requiere de la confección de modelos adaptados a la edad de los estudiantes. A estas características habría que añadir su evolución a lo largo del tiempo geológico, su impacto en la historia de la humanidad o cómo el vulcanismo contribuye a la conformación del relieve terrestre.

En este trabajo pretendemos mostrar, desde una perspectiva múltiple, algunas de las contribuciones al conocimiento de esta temática, tanto desde el punto de vista científico como didáctico y social, en la creencia de que este enfoque puede contribuir a un tratamiento más global y fundamentado en las aulas por parte del profesorado. También debemos aclarar que no es nuestra intención abordar una revisión sistemática de la literatura, sino más bien una descripción narrativa de algunas posibilidades didácticas de la temática de los volcanes.

\section{Dimensión científica}

Los volcanes son una manifestación de la dinámica interna de la Tierra, por lo que su estudio implica también hacerlo con la estructura de la Tierra y su funcionamiento, al menos en su parte más externa (corteza y manto). Esto conlleva abordar tres parcelas de conocimientos: la estructura y arquitectura volcánica, los materiales implicados desde el origen del magmatismo hasta sus productos, y los procesos implicados desde la generación del magma hasta las erupciones (Blake 2005).

Desde otro punto de vista, Dal (2006, p. 42), citando a diversos autores, indica que el vulcanismo se puede estudiar desde tres ángulos de aproximación, correspondientes a cada uno de los campos particulares, que son:

- El ángulo humano, donde se encuentra todo lo que corresponde a la relación entre el ser humano y los volcanes: consecuencias positivas o negativas, con sus aspectos catastróficos, emocionales o sensoriales; métodos de estudio del fenómeno y trabajo de los vulcanólogos; y geología y geofísica aplicada.

- El ángulo descriptivo, en el que se estudian todos los objetos geológicos relacionados con el vulcanismo, por ejemplo, los productos de la erupción.

- El ángulo explicativo, donde se vincula el fenómeno a la estructura del globo, los mecanismos relacionados y las transformaciones de la materia.

Se han dado diversas definiciones de lo que es un volcán. Así, la RAE establece que es una «abertura en la tierra, y más comúnmente en una montaña, por donde salen de tiempo en 
tiempo humo, llamas y materias encendidas o derretidas». Sigurdsson, Bruce, Stephen, John y Haxel (2000, p. 42) lo definen como «un punto de salida por donde el magma puede llegar a la superficie de manera intermitente o continua», lo que coincide, en parte, con la definición de la RAE. Para Martí y Folch (1999, p. 194) «un volcán hay que definirlo como un punto de la superficie terrestre donde tiene lugar la salida al exterior de material rocoso fundido (magma) generado en el interior de la Tierra, en zonas del manto superior o de la corteza terrestre, y ocasionalmente de material no magmático, y en el que la acumulación de parte de estos productos alrededor del centro emisor (boca eruptiva) puede dar lugar a relieves positivos con morfologías diversas», lo que añade una dimensión descriptiva y morfológica. Por otro lado, Pujadas, Brusi y Pedrinaci (1999, p. 201) hacen una propuesta más globalizadora y evolutiva: «un volcán es la evidencia geológica de la llegada de material magmático a un lugar de la superficie terrestre (o de otro cuerpo planetario). Debe tenerse en cuenta que es un término general que hace referencia a la manifestación magmática en sí misma, pero también a todas las estructuras y materiales (chimenea, ramificaciones de esta, edificios volcánicos construidos, coladas de lava, depósitos piroclásticos,...) que se forman y permanecen en el registro geológico después de finalizar la actividad volcánica». Esta última definición permitiría la inclusión de las dorsales oceánicas, los mayores edificios volcánicos del planeta y que tienen un carácter más fisural que meramente puntual, aunque generalmente son olvidados por ocurrir bajo agua. Por otra parte, no hay que olvidar que el vulcanismo es solo la punta del iceberg de los fenómenos magmáticos, puesto que se estima que solo, dependiendo del contexto, entre el 3 y 10\% de los magmas llegan realmente a superficie (Putirka 2017).

Otras definiciones obtenidas de las diez primeras referencias en el buscador de Google con la palabra clave volcán fueron analizadas por Carrillo, García, Perales y Vázquez (2021) evidenciando la heterogeneidad de su tratamiento, haciendo un principal énfasis en sus características geofísicas y en los procesos de erupción, y menos en las causas de la misma. También habría que estar abiertos a nuevos conceptos, como los de supervolcán o supererupción. Esta última sería una erupción que expulsa más de $450 \mathrm{~km}^{3}$ de magma (1000 $\mathrm{km}^{3}$ de productos volcánicos de baja densidad) y que implica un magma rico en sílice y la formación de grandes calderas (Miller y Wark 2008). Estas supererupciones, aunque no han tenido lugar en época histórica y su frecuencia se estima en cada 100000 años, conllevan elevar en órdenes de magnitud la amenaza de los volcanes, convirtiéndola en global (Self y Blake 2008), aunque la inmensidad del tiempo geológico nos impide percibir ese riesgo a escala humana.

La complejidad que envuelve el proceso eruptivo, dado el gran número de parámetros que intervienen en él, hace muy difícil definir y clasificar los volcanes, puesto que pueden presentar una erupción con mecanismos muy diferentes a los anteriores e incluso presentar variaciones drásticas durante la propia erupción. A pesar de ello, el agente desencadenante de la erupción es el propio magma condicionado por el contexto geodinámico y geotectónico, el cual, dependiendo de sus propiedades físico-químicas, permitirá que sean más o menos explosivas (Aulinas-Juncà, Rodríguez-González y Planagumà-Guàrdia 2015).

Estas definiciones, junto con un análisis de contenido del concepto llevado a cabo y consensuado por expertos en esta temática (dos físicos y dos geólogos, autores de este trabajo), nos han permitido identificar inicialmente las siguientes dimensiones del concepto (Tabla 1). 
Tabla 1. Propuesta de dimensiones del concepto de volcán y descriptores.

\begin{tabular}{|c|c|}
\hline Dimensiones & Algunos descriptores \\
\hline Ubicación y distribución & $\begin{array}{l}\text { Relación con la tectónica de placas y volcanes (con énfasis en volcanes famosos } \\
\text { actuales o históricamente). }\end{array}$ \\
\hline $\begin{array}{l}\text { Tipos de erupciones y } \\
\text { tipos de volcanes }\end{array}$ & $\begin{array}{l}\text { Composición del magma, mecanismos de erupción, estado de los materiales } \\
\text { implicados y tipos de volcanes, ciclo de las rocas, modificación del relieve, relación } \\
\text { con los terremotos. }\end{array}$ \\
\hline Causas & Origen del magma y condiciones que favorecen la erupción \\
\hline $\begin{array}{l}\text { Riesgo y peligro } \\
\text { volcánico }\end{array}$ & $\begin{array}{l}\text { Efectos sobre el medio ambiente (clima) y las sociedades humanas, el riesgo de los } \\
\text { supervolcanes }\end{array}$ \\
\hline $\begin{array}{l}\text { Estudio y predicción de } \\
\text { las erupciones volcánicas }\end{array}$ & Investigación actual \\
\hline Recursos volcánicos & $\begin{array}{l}\text { Aprovechamiento de los recursos geotermales, de materiales volcánicos e } \\
\text { hidrotermales, beneficios agrícolas }\end{array}$ \\
\hline Otros & $\begin{array}{l}\text { Implicaciones lingüísticas, históricas (de la Tierra y de la Humanidad), artísticas, } \\
\text { emocionales... }\end{array}$ \\
\hline
\end{tabular}

Esta tabla constituirá un primer referente con el que contrastar las propuestas educativas formales e informales disponibles, así como sugerir un tratamiento diferenciado sobre volcanes en las etapas del currículo.

En la figura 1 hemos representado un mapa conceptual que intenta recoger las dimensiones anteriores.

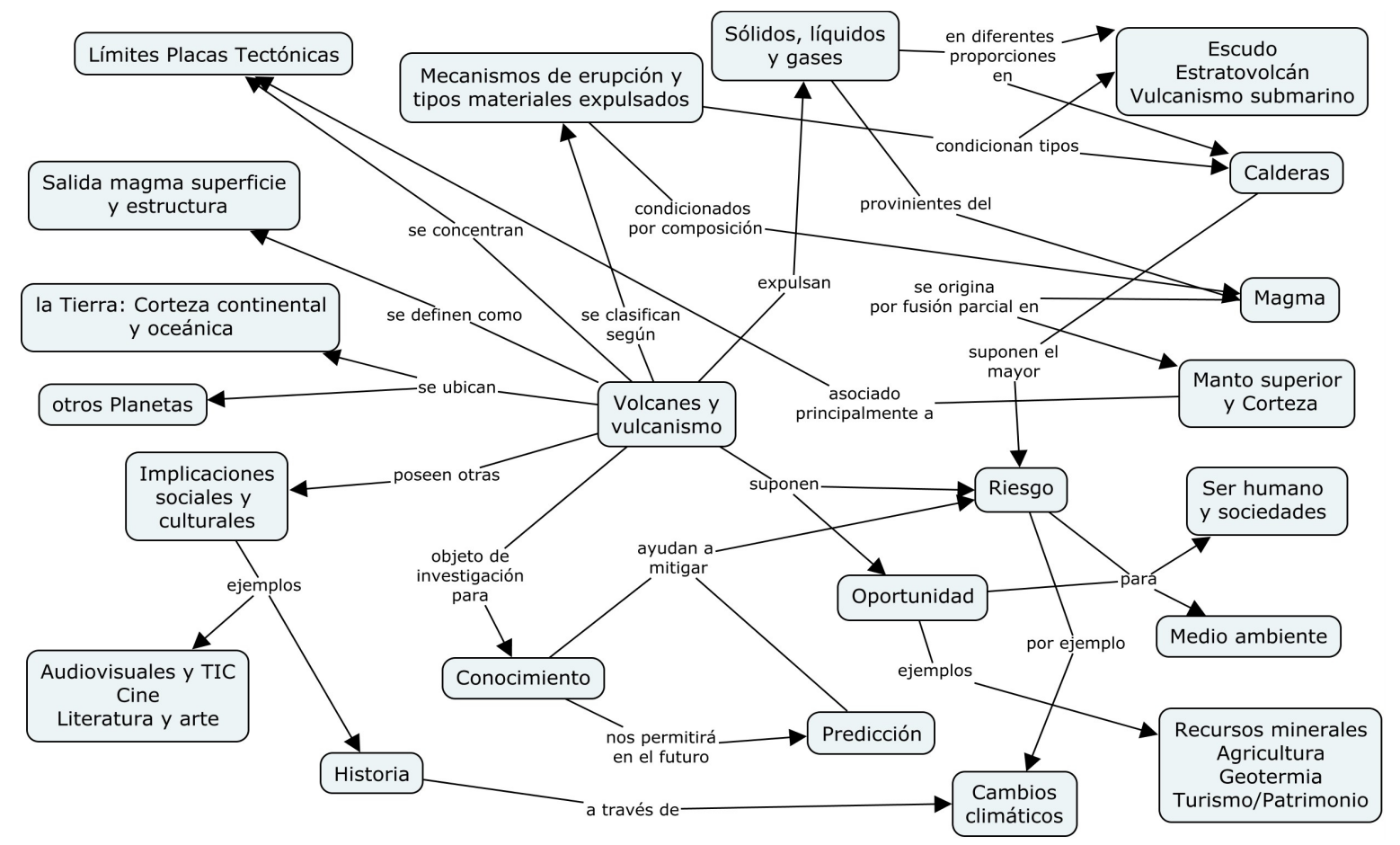

Figura 1. Mapa conceptual de un volcán y sus dimensiones.

\section{Dimensión didáctica}

De las distintas posibilidades que esta dimensión nos proporciona, vamos a centrarnos en cuatro de ellas que estimamos poseen suficiente impacto en el desarrollo de esta temática en las aulas: el currículo prescrito, el implementado (libros de texto), las ideas previas que suelen 
mantener los estudiantes sobre los volcanes, el vulcanismo y los procesos que los originan, así como en las intervenciones relativas a su enseñanza y aprendizaje.

\section{El currículo}

Si analizamos en primer lugar la presencia de este contenido en el currículo de enseñanzas mínimas de Educación Primaria (Real Decreto 126/2014) en España, no encontramos referencia explícita al tópico que nos afecta, solo las siguientes referencias indirectas en el Bloque 2 de Ciencias Sociales, El mundo en que vivimos.

Tabla 2. Referencias curriculares indirectas a los volcanes en el currículo de Educación Primaria.

\begin{tabular}{|c|c|c|}
\hline Contenido & Criterios de evaluación & $\begin{array}{c}\text { Estándares de aprendizaje } \\
\text { evaluables }\end{array}$ \\
\hline $\begin{array}{l}\text { La Litosfera: } \\
\text { características y } \\
\text { tipos de rocas. } \\
\text { Rocas y minerales: } \\
\text { Propiedades usos y } \\
\text { utilidades. } \\
\text { La diversidad } \\
\text { geográfica de los } \\
\text { paisajes de España: } \\
\text { relieve e } \\
\text { hidrografía. } \\
\text { La diversidad } \\
\text { geográfica de los } \\
\text { paisajes de } \\
\text { Europa: relieve, } \\
\text { climas, e } \\
\text { hidrografía }\end{array}$ & $\begin{array}{l}\text { 13. Adquirir el concepto de litosfera, conocer } \\
\text { algunos tipos de rocas y su composición } \\
\text { identificando distintos minerales y algunas de } \\
\text { sus propiedades. } \\
\text { 14. Explicar que es un paisaje e identificar los } \\
\text { principales elementos que lo componen. } \\
\text { 15. Describir las características del relieve de } \\
\text { España y su red hidrográfica, localizándolos } \\
\text { en un mapa. }\end{array}$ & $\begin{array}{l}\text { 13.1. Observa, identifica, y explica la } \\
\text { composición de las rocas nombrando } \\
\text { algunos de sus tipos. } \\
\text { 13.2. Identifica y explica las } \\
\text { diferencias entre rocas y minerales, } \\
\text { describe sus usos y utilidades, } \\
\text { clasificando algunos minerales según } \\
\text { sus propiedades. } \\
\text { 14.1. Define paisaje, identifica sus } \\
\text { elementos y explica las características } \\
\text { de los principales paisajes de España y } \\
\text { Europa, valorando su diversidad. } \\
\text { 15.1. Localiza en un mapa las } \\
\text { principales unidades del relieve de } \\
\text { España y sus vertientes hidrográficas. } \\
\text { 15.2. Sitúa en un mapa los mares, } \\
\text { océanos y los grandes ríos de España. } \\
\text { 16.1. Localiza en un mapa el relieve } \\
\text { de Europa, sus vertientes } \\
\text { hidrográficas y sus climas. } \\
\text { 16.2. Reconoce los principales rasgos } \\
\text { del relieve, los ríos y el clima de } \\
\text { Europa. }\end{array}$ \\
\hline
\end{tabular}

Queda claramente evidenciada la ausencia del fenómeno del vulcanismo y, además, se incorporaría a la asignatura troncal de Ciencias Sociales, en lugar de en la de Ciencias de la Naturaleza, con la que existe una relación más estrecha desde el punto de vista epistemológico.

Su tratamiento en Primaria adolece, como vemos, de un suficiente respaldo curricular explícito (aunque implícitamente a través de los materiales y la morfología está considerado), aparte de la inadecuada ubicación dentro de las materias de dicha etapa educativa, a lo que habría que añadir las deficiencias que suele conllevar la formación científica del grado universitario de Primaria. Surge entonces un aparente contrasentido entre un fenómeno natural llamativo para el alumnado y la falta de respuesta educativa.

En el caso de la Educación Secundaria Obligatoria (Real Decreto 1105/2014, de 26 de diciembre) y la asignatura Biología y Geología. $1^{\circ}$ y $3^{\circ} \mathrm{ESO}$, para el Bloque 5, El relieve terrestre y su evolución, encontramos los contenidos de la Tabla 3. 
Tabla 3. Referencias curriculares directas a los volcanes en el currículo de Educación Secundaria Obligatoria.

\begin{tabular}{|c|c|c|}
\hline Contenido & Criterios de evaluación & $\begin{array}{c}\text { Estándares de aprendizaje } \\
\text { evaluables }\end{array}$ \\
\hline $\begin{array}{l}\text { Manifestaciones de la } \\
\text { energía interna de la Tierra. } \\
\text { Origen y tipos de magmas. } \\
\text { Actividad sísmica y } \\
\text { volcánica. Distribución de } \\
\text { volcanes y terremotos. Los } \\
\text { riesgos sísmico y volcánico. } \\
\text { Importancia de su } \\
\text { predicción y prevención. }\end{array}$ & $\begin{array}{l}\text { 11. Analizar las actividades sísmica y } \\
\text { volcánica, sus características y los } \\
\text { efectos que generan. } \\
\text { 13. Valorar la importancia de conocer } \\
\text { los riesgos sísmico y volcánico y las } \\
\text { formas de prevenirlo. }\end{array}$ & $\begin{array}{l}\text { 11.2. Relaciona los tipos de erupción } \\
\text { volcánica con el magma que los } \\
\text { origina y los asocia con su } \\
\text { peligrosidad. } \\
\text { 13.1. Valora el riesgo sísmico y, en su } \\
\text { caso, volcánico existente en la zona en } \\
\text { que habita y conoce las medidas de } \\
\text { prevención que debe adoptar. }\end{array}$ \\
\hline
\end{tabular}

De una manera indirecta, habría también una referencia a través de los minerales y rocas que pueden ser productos volcánicos (La geosfera. Estructura y composición de corteza, manto y núcleo. Los minerales y las rocas: sus propiedades, características y utilidades). $\mathrm{Y}$ en $4^{\circ}$ de ESO, en una materia no obligatoria, se introduce en la teoría de la tectónica de placas que es la que explica en último término los procesos volcánicos.

Como muestra del desarrollo curricular a nivel autonómico, para Andalucía el segundo nivel de desarrollo curricular contempla solo como novedad en la asignatura de Biología y Geología de $3^{\circ}$ de ESO y el mismo bloque anterior, la inclusión del criterio de evaluación 12: "Relacionar la actividad sísmica y volcánica con la dinámica del interior terrestre y justificar su distribución planetaria".

Si comparamos este último currículo con las dimensiones presentes en la Tabla 1 constatamos que se podrían ver reflejadas todas las dimensiones establecidas para los volcanes, excepto las dos últimas, es decir, los recursos volcánicos y otros (Tabla 4).

Tabla 4. Presencia de las dimensiones del concepto de volcán (Tabla 1) y sus descriptores en la Educación Secundaria Obligatoria en el currículo de Andalucía.

\begin{tabular}{|l|l|}
\hline \multicolumn{1}{|c|}{ Dimensiones } & \multicolumn{1}{c|}{ Contenidos / criterios de evaluación } \\
\hline $\begin{array}{l}\text { Ubicación y } \\
\text { distribución }\end{array}$ & $\begin{array}{l}\text { Distribución de volcanes y terremotos. } \\
\text { Relacionar la actividad sísmica y volcánica con la dinámica del interior terrestre y } \\
\text { justificar su distribución planetaria. }\end{array}$ \\
\hline $\begin{array}{l}\text { Tipos de erupciones y } \\
\text { tipos de volcanes }\end{array}$ & Actividad sísmica y volcánica. \\
\hline $\begin{array}{l}\text { Causas } \\
\text { Riesgo y peligro } \\
\text { volcánico }\end{array}$ & Manifestaciones de la energía interna de la Tierra. Origen y tipos de magmas. \\
\hline $\begin{array}{l}\text { Predicción de las } \\
\text { erupciones volcánicas }\end{array}$ & Importancia de su predicción y prevención. \\
\hline
\end{tabular}

Por consiguiente y, al contrario de lo que ocurría para Primaria, el vulcanismo dispone de un amplio margen de tratamiento en las aulas en esta etapa educativa. 


\section{Los libros de texto}

Los volcanes han sido, tradicionalmente, objeto de enseñanza. A pesar de ello, no resulta especialmente abundante la producción en esta línea de investigación sobre el tópico que nos afecta en los libros de texto. Mostraremos algunos ejemplos de distinta naturaleza:

Dal (2006) denuncia como un desencadenante de las ideas previas de los estudiantes la naturaleza de las explicaciones que acompañan a los diagramas en los libros de texto y la forma en que el profesor las utiliza en el aula. Plantea como primer ejemplo la existencia de una capa de magma debajo de la corteza terrestre, mientras que de hecho el manto no se encuentra en estado líquido. Así, según el autor, en un libro de texto, para ayudar a los estudiantes a comprender las corrientes de convección en el manto, se propone un modelo en forma de diagramas con notas adjuntas que muestra agua (por lo tanto, un líquido) calentada por una resistencia eléctrica. El segundo ejemplo es el de la formación de un cono volcánico por ascenso, sin que los productos de la erupción volcánica intervengan. En otro libro se incluye un diagrama de "Pronóstico de erupciones volcánicas" acompañado de las siguientes descripciones: "Período 1 comienza la hinchazón del volcán, Período 2 pico de hinchazón - las distancias horizontal y vertical se alargan - la pendiente aumenta, Período 3 Erupción Deflación - la pendiente disminuye". Sin embargo, no se da una escala para indicar el valor relativo de esta hinchazón y para situar el fenómeno en relación con la boca del volcán. Para el autor estas explicaciones, que van de la mano de los esquemas, tienen como objetivo facilitar la comprensión de fenómenos relativamente inaccesibles gracias a simplificaciones o analogías; pero en ambos casos, si el docente no tiene cuidado, las concepciones alternativas pueden consolidarse o generarse por la enseñanza.

Por otro lado, Eddif, Selmaoui y Chakour (2018) analizaron dos manuales de Educación Secundaria separados por un intervalo de trece años sobre el patrimonio geológico del territorio marroquí relativo al concepto de volcán. Una síntesis de los objetivos que se planteaban en ambos libros (conjuntamente) es: a) Diferenciar entre los dos tipos de erupciones: efusivas y explosivas; b) Conocer la relación entre la distribución de los volcanes y la tectónica de placas; c) Comprender el mecanismo de extensión, subducción y placa oceánica tectónica; d) Especificar los tipos de erupciones que caracterizan los contextos geodinámicos de extensión y subducción; e) Especificar el origen del magma y los componentes del volcán; f) Tomar conciencia del peligro que suponen los volcanes; g) Realizar manipulaciones para comprender el mecanismo de erupción volcánica. No obstante, los resultados obtenidos por estos autores evidenciaron la existencia de grandes lagunas en el tratamiento del vulcanismo.

En un sentido más creativo, Kim, Yang, Kang y Kim (2010) diseñaron un libro de texto digital con voz y texto para enseñar volcán y roca para quinto grado, incluyendo un método de simulación con el objetivo de favorecer la participación de los usuarios y el efecto educativo. Estos pueden observar procesos prolongados de fenómenos naturales como la creación de un volcán a través de la simulación $3 \mathrm{D}$, lo que fue valorado positivamente por parte de los estudiantes.

El estudio más completo fue el realizado por King (2010). En este trabajo se analizó el contenido de Ciencias de la Tierra de todos los libros de texto de ciencias de Secundaria y publicaciones relacionadas que se utilizan en Inglaterra y Gales (51 en total), identificando más de 500 casos de conceptos erróneos. Para los 15 conceptos erróneos más frecuentes se dan ejemplos de citas de los libros de texto, junto con la opinión de consenso científico, una discusión y un ejemplo de un concepto erróneo de importancia similar en otra área de la ciencia. Presentamos en la Tabla 5 algunos de ellos. 
Tabla 5. Ejemplos de errores encontrados en libros de texto. Fuente: adaptado de King (2010).

\begin{tabular}{|c|c|c|}
\hline $\begin{array}{c}\text { Error o } \\
\text { sobresimplificación }\end{array}$ & Criterios de evaluación & $\begin{array}{c}\text { Estándares de aprendizaje } \\
\text { evaluables }\end{array}$ \\
\hline $\begin{array}{l}\text { El manto es semi-líquido o } \\
\text { semi-sólido }\end{array}$ & $\begin{array}{l}\text { El material que entra en el manto líquido } \\
\text { puede emerger a través de volcanes para } \\
\text { formar rocas igneas. }\end{array}$ & $\begin{array}{l}\text { La astenosfera (derivada del griego } \\
\text { 'esfera débil') es la capa dúctil } \\
\text { relativamente débil en el manto } \\
\text { superior, inmediatamente debajo de la } \\
\text { litosfera. Aunque es sólida a tasas de } \\
\text { deformación normales, como el resto } \\
\text { del manto no litosférico, puede } \\
\text { deformarse lentamente en estado } \\
\text { sólido }\end{array}$ \\
\hline $\begin{array}{l}\text { El basalto y el granito pueden } \\
\text { formarse a partir del mismo } \\
\text { magma, p. ej. Un solo magma } \\
\text { puede producir granito o basalto o } \\
\text { el granito proviene de los volcanes. }\end{array}$ & $\begin{array}{l}\text { La roca fundida que emerge a través de los } \\
\text { volcanes se llama lava. A medida que se } \\
\text { enfría, forma una variedad de sólidos que se } \\
\text { conocen como roca ignea... - un ejemplo es el } \\
\text { granito-. }\end{array}$ & $\begin{array}{l}\text { El granito y el basalto son } \\
\text { químicamente muy diferentes y } \\
\text { generalmente no se encuentran } \\
\text { relacionados. Cuando el manto funde } \\
\text { parcialmente se forma magma rico en } \\
\text { hierro y pobre en sílice que, } \\
\text { generalmente produce basalto si se } \\
\text { enfría rápidamente en la superficie o } \\
\text { gabro si se enfría lentamente en } \\
\text { profundidad. Cuando la corteza se } \\
\text { funde parcialmente se forma un } \\
\text { magma rico en sílice. Rara vez entra en } \\
\text { erupción como lava, sino como cenizas } \\
\text { o piedra pómez. Por lo general, este } \\
\text { magma cristaliza lentamente bajo tierra } \\
\text { para formar granito. }\end{array}$ \\
\hline
\end{tabular}

Otros errores relacionados tienen que ver con las rocas ígneas y los procesos de formación: a) formas de granito en los volcanes; b) definiciones de ígneo; c) el magma proviene solo del manto. Otros errores vinculados a las placas tectónicas tuvieron que ver con una pobre comprensión de: a) la naturaleza de los continentes y océanos; b) el concepto de tectónica de placas; c) las conexiones entre terremotos, volcanes y movimiento de las placas.

Si comparamos los resultados de este estudio con algunas de las dimensiones de los volcanes (Tabla 1), podemos elaborar la Tabla 6.

Tabla 6. Comparación entre las dimensiones propuestas para un volcán y los errores detectados en el trabajo de King (2010).

\begin{tabular}{|c|c|c|}
\hline $\begin{array}{l}\text { Ubicación y } \\
\text { distribución }\end{array}$ & $\begin{array}{l}\text { Relación con la tectónica de placas } \\
\text { y volcanes (con énfasis en } \\
\text { volcanes famosos actuales o } \\
\text { históricamente). }\end{array}$ & $\begin{array}{l}\text { Escasa comprensión del concepto de tectónica de } \\
\text { placas. }\end{array}$ \\
\hline
\end{tabular}


Estos datos nos llevan a entender algunas de las ideas previas de los estudiantes que abordamos en el siguiente apartado, dado que son las propias fuentes (y más generalizadas) de conocimiento científico las que contienen algunos de los errores más comunes detectados en la literatura educativa entre los estudiantes.

\section{Las ideas previas}

En este caso vamos a exponer de una forma organizada las principales aportaciones a la dimensión didáctica de los volcanes a partir de una revisión bibliográfica efectuada.

Comenzaremos con trabajos realizados para diagnosticar las ideas previas de los estudiantes (Anexo 1). A partir de dicha revisión hemos agrupado y relacionado las ideas previas que difieren de las científicas con las dimensiones establecidas en la Tabla 1, habiéndose hallado conexión con las cuatro primeras (Tabla 7).

Tabla 7. Comparación entre las dimensiones propuestas para un volcán y las ideas previas detectadas en la literatura.

\begin{tabular}{|c|c|c|}
\hline Dimensiones & Algunos descriptores & Ideas previas \\
\hline $\begin{array}{l}\text { Ubicación y } \\
\text { distribución }\end{array}$ & $\begin{array}{l}\text { Relación con la tectónica de placas } \\
\text { y volcanes (con énfasis en volcanes } \\
\text { famosos actuales o históricamente). }\end{array}$ & $\begin{array}{l}\text { - Los volcanes solo ocurren en islas, están } \\
\text { asociados con climas cálidos y solo ocurren a } \\
\text { lo largo del ecuador. } \\
\text { - Los volcanes solo se forman cerca de } \\
\text { cuerpos de agua. } \\
\text { - Aparecen volcanes en zonas de terreno } \\
\text { rocoso. } \\
\text { - Los volcanes se encuentran principalmente } \\
\text { en ambientes terrestres. } \\
\text { - No se conoce su relación con las placas } \\
\text { tectónicas y su dinámica. } \\
\text { - Los volcanes son creados por el hombre. }\end{array}$ \\
\hline $\begin{array}{l}\text { Tipos de erupciones } \\
\text { y tipos de volcanes }\end{array}$ & 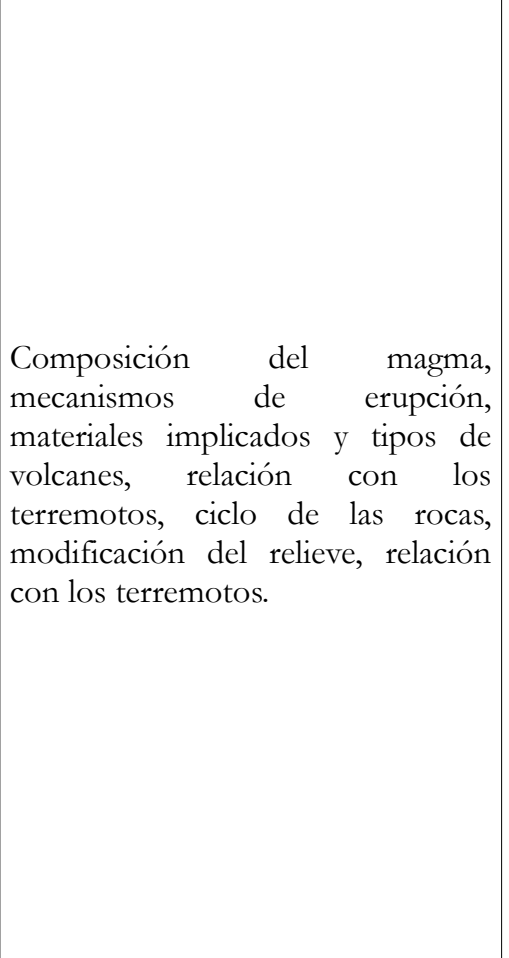 & $\begin{array}{l}\text { - Un volcán es un cono volcánico sin detalle } \\
\text { estructural. } \\
\text { - Cono lleno de lava. } \\
\text { - Presencia de un pozo que une la estructura } \\
\text { volcánica con un reservorio, punto profundo } \\
\text { de origen de la lava. } \\
\text { - Un eje que une el volcán con una capa o } \\
\text { capa de lava; origen profundo, pero que a } \\
\text { menudo evoca la corteza terrestre, el sótano y las } \\
\text { capas internas de la Tierra. } \\
\text { - Confusión entre erupciones volcánicas y } \\
\text { terremotos. } \\
\text { - No se comprende el funcionamiento interno } \\
\text { de un volcán, lo que controla la actividad } \\
\text { explosiva, el papel de la sílice en la actividad } \\
\text { explosiva. } \\
\text { - Creen que todas las erupciones volcánicas } \\
\text { son violentas y están acompañadas de lava. } \\
\text { - Los volcanes están formados por } \\
\text { deslizamientos de tierra. } \\
\text { - Los volcanes son creados por impactos de } \\
\text { meteoritos. }\end{array}$ \\
\hline
\end{tabular}


Tabla 7. Continuación.

\begin{tabular}{|c|c|c|}
\hline Dimensiones & Algunos descriptores & Ideas previas \\
\hline Causas & $\begin{array}{l}\text { Origen del magma y condiciones } \\
\text { que favorecen la erupción }\end{array}$ & $\begin{array}{l}\text { - No saben qué causó las erupciones volcánicas } \\
\text { ('sucedió solo') u ofrecen alguna causa humana. } \\
\text { - Causas naturalistas, pero excéntricas (por } \\
\text { ejemplo, el volcán se llena demasiado de lava) o } \\
\text { se acercan a cierto grado de conocimiento } \\
\text { científico (por ejemplo, calor interno del núcleo } \\
\text { o magma forzado por la presión del gas debajo } \\
\text { de la Tierra). } \\
\text { - Lava con un origen superficial relacionado } \\
\text { con el volcán (interior del volcán, en la cima del } \\
\text { volcán). } \\
\text { - Origen mayor (pero vago) que incluye la lava } \\
\text { está bajo tierray sube para llenar el volcán. } \\
\text { - El magma que entra en erupción a través de } \\
\text { los volcanes se origina en el núcleo de la Tierra. } \\
\text { - Lo señalan simultáneamente en el núcleo, en } \\
\text { el núcleo interno y/o lo representan como una } \\
\text { capa continua en el manto. } \\
\text { - Se concibe el magma formando una capa en el } \\
\text { interior terrestre. }\end{array}$ \\
\hline $\begin{array}{l}\text { Riesgo y peligro } \\
\text { volcánico }\end{array}$ & $\begin{array}{l}\text { Efectos sobre el medio ambiente } \\
\text { (clima) y las sociedades humanas, el } \\
\text { riesgo de los supervolcanes. }\end{array}$ & $\begin{array}{l}\text { - No se conocen los efectos de la actividad } \\
\text { volcánica en el medio ambiente circundante y la } \\
\text { civilización humana. } \\
\text { - No están familiarizados con los peligros } \\
\text { secundarios como la principal causa de muerte } \\
\text { y lesiones por erupciones volcánicas. } \\
\text { - Los volcanes son creados por el } \\
\text { calentamiento global. }\end{array}$ \\
\hline
\end{tabular}

Los resultados mostrados en la Tabla 7 pueden constituir una valiosa guía para el profesorado de manera que pueda incidir en aquellas ideas más alejadas de las aceptadas por la Ciencia y que, como hemos visto en el apartado de libros de texto, incluso algunas de ellas se presentan en estos materiales de enseñanza (Tabla 6 ).

\section{Intervenciones educativas}

Como señalan García-Yeguas y Vílchez (2021), se da una llamativa escasez de estudios publicados en revistas de la WOS sobre enseñanza y aprendizaje del fenómeno volcánico. En este apartado recogeremos algunos ejemplos de acciones educativas en un sentido amplio (estrategias, recursos...) que nos permitan aproximarnos a una mejora de la enseñanza de los volcanes y conceptos asociados.

En el trabajo de Ejarque, Bravo y Mazas Gil (2016) las autoras plantean una actividad de modelización basada en un modelo a escala de las capas de la Tierra, a fin de tratar de modificar las ideas previas de una muestra de estudiantes de Secundaria acerca del sobredimensionamiento de la corteza terrestre y la procedencia del magma. Dicha actividad se mostró eficaz en la corrección de la primera idea previa pero no en el caso de la segunda, dado que los estudiantes siguen pensando que el magma procede del núcleo terrestre. En palabras de las autoras: «la mayoría de los alumnos presupone que existe una comunicación directa 
entre el núcleo y el exterior terrestre; es decir, creen que hay canales que conectan los focos volcánicos y la corteza» (p. 25). En cuanto a las posibles alternativas, señalan que no resulta suficiente solicitar al alumnado representar dónde se encuentra la cámara magmática de un volcán para ayudarle a darse cuenta de la poca profundidad que alcanza, proponiendo que debe abordarse de una forma explícita comparando la composición del magma (silicatada) con la del núcleo (férrica).

Carrillo-Rosúa, Vílchez-González y Fernández-Oliveras (2014) y Fernández-Oliveras, VílchezGonzález y Carrillo-Rosúa (2016) proponen una actividad de indagación y uso de pruebas, focalizada también en el origen del magma, para docentes de Primaria en formación. En este caso la idea clave es el uso de pruebas para el desarrollo de la competencia científica, partiendo de información de gráficas, de modelización analógica y de observación de rocas. Se comprobó que con la actividad se mejoraba la localización del magma que sale por los volcanes y la propuesta fue valorada positivamente por los participantes, quienes la encontraron útil tanto para su propia formación como para la de su futuro alumnado de Educación Primaria.

Recientemente, Vergara-Díaz, Bustamante, Pinto y Cofré (2020) estudiaron la modificación de las ideas previas sobre la dinámica terrestre en estudiantes de Educación Secundaria a través de actividades de indagación y uso de modelos analógicos. Para trabajar el contenido de los volcanes los autores proponen a los estudiantes crear un volcán con papel higiénico y pegamento e inyectan mezclas con diferentes viscosidades que son empujadas hacia afuera y a través de la cima del volcán. De esta manera, es posible comparar cómo mezclas ligeramente viscosas y muy viscosas descienden de la parte superior del volcán. La intención de esta actividad es que los estudiantes aprendan que la forma del volcán depende de la viscosidad de la lava y que los volcanes no son montañas perforadas. Los resultados obtenidos demuestran que las estrategias de indagación y el uso de modelos analógicos mejoran la comprensión de los estudiantes y alcanzan una eficiencia que casi duplica a la de metodologías tradicionales.

Por otra parte, Lee y Bae (2008), mediante un estudio de caso, emplearon una estrategia de aprendizaje basado en problemas (ABP) para implementar el estudio de los volcanes en estudiantes de $8^{\circ}$ grado, seleccionando dos situaciones volcánicas reales y centrándose no solo en los resultados de la estrategia en los estudiantes sino también en la formación de un futuro profesor en prácticas frente a esta metodología de enseñanza.

Un ejemplo de recurso didáctico es el proporcionado por Boudreaux et al. (2009), quienes diseñaron un entorno de aprendizaje de realidad virtual sobre la actividad volcánica que sumerge a los estudiantes en una simulación científicamente precisa de sistemas volcánicos. Los estudiantes pueden generar y manipular erupciones volcánicas en tiempo real con monitoreo de datos para explorar los efectos de las condiciones cambiantes. De cualquier modo, los autores no informan de la evaluación del aprendizaje logrado.

Desde otro punto de vista, Harpp, Koleszar y Geist (2005) idearon una llamativa simulación de una explosión volcánica con materiales reales, a partir de nitrógeno líquido, y que permitiría a los estudiantes utilizar cálculos para describir los principios físicos de la erupción.

Onida y Segalini (2006) elaboraron una secuencia de enseñanza para escolares de Primaria a partir del visionado de un documental sobre distintos escenarios terrestres, tras el cual los escolares decidieron estudiar los volcanes. Los objetivos de la intervención fueron promover la comprensión de: a) la fusión de las rocas del manto (cambio de estado) y la formación del magma; b) el movimiento de ascenso del magma en relación con el cambio densidad/peso específico del material implicado; c) la removilización del magma de la cámara magmática hacia la superficie en relación a la presión (por la llegada de un nuevo magma o por 
disminución de la presión confinante por la liberación de gas); y d) la presencia del gas en el magma como elemento que condiciona la explosividad de las erupciones.

Posteriormente, dichos objetivos se concretaron aún más en función de la reacción de los escolares en los siguientes: a) una vez ha salido la lava, ésta discurre, más o menos lentamente (viscosidad) y después se enfría (más o menos rápidamente) y se vuelve sólida: roca volcánica; b) el edificio volcánico se forma seguidamente a la erupción (bien es cierto que no hay que identificar los edificios volcánicos con el de estratovolcán como suele ocurrir (Francek 2012; Vílchez-González, Prudencio, Urbano-Rodríguez, Ibáñez y Carrillo-Rosúa 2014) y está hecho de una cámara magmática, un conducto volcánico, un cono de forma y dimensiones variables y un cráter; c) comprender la diferencia entre magma y lava (ligada a la pérdida de gas durante la salida del conducto) y entre lava y roca volcánica (ligada a la solidificación) (p. 250). Para alcanzar dichos objetivos propusieron a los escolares construir un modelo de volcán con algunas experiencias manipulativas en las que apoyarse, trabajando colaborativamente y finalizando con la elaboración de un esquema final apoyado en imágenes. Los resultados en términos de aprendizaje fueron positivos, sin embargo pocos escolares han sabido reconstruir las causas que provocan el ascenso del magma y la erupción. Esto sin duda es atribuible para las autoras a los numerosos fenómenos y conceptos físicos implicados (como fusión y solidificación; transmisión de calor y formación de un gradiente de temperatura, densidad y presión...).

Con las referencias anteriores hemos querido mostrar algunas estrategias y recursos que pueden ayudar al docente a afrontar con ciertas garantías la enseñanza de un tema complejo, no solo por la dificultad de acceder al objeto-problema, sino por la interacción de variables que intervienen en la actividad volcánica y sus consecuencias. En ese sentido, estrategias como la indagación y actividades de modelización, junto con el apoyo audiovisual en un sentido amplio (videos, programas de realidad virtual, figuras...) parecen mostrarse útiles.

\section{Dimensión social}

Los volcanes y el vulcanismo han concitado un indudable interés social que se ha manifestado en formas diversas. Sin ánimo de ser sistemáticos, mencionaremos algunas de ellas, a modo de ejemplo, no relacionadas directamente con la educación formal pero que pueden constituir un banco de ideas para realizar un planteamiento intersdisciplinar coherente con ABP, CTS o STEAM del tratamiento de los volcanes, lo que sin duda puede constituir un elemento motivador para el alumnado.

\section{Historia}

Son numerosas las erupciones a la largo de la historia de la Tierra, y sus consecuencias para la Humanidad no solo han tenido un carácter local (p. ej., destrucción de Pompeya y Herculano en el 79 d.C.), sino que también provocaron o indujeron cambios globales a través de su afectación en el clima. Así, por ejemplo, tres erupciones volcánicas entre los años 536 y 547 de nuestra era provocaron la llamada Edad de Hielo de la Antigüedad tardía y que se prolongó durante décadas, con catastróficas consecuencias sociales y ambientales (Büntgen et al. 2016).

En el año 1883 la erupción del Krakatoa fue quizás la primera catástrofe global percibida como tal con impacto mediático en todo el mundo. Fue acompañada de un ruido generado que se considera el sonido más fuerte que se ha registrado en la historia, produciéndose un tsunami cuyas olas alcanzaron más de 30 metros de altura, causando más de 36.000 muertos y provocando un sensible efecto climático (Dörries 2003).

Más aún, relativamente pequeñas erupciones, en nuestras sociedades altamente tecnificadas, pero muy vulnerables, pueden tener un gran efecto. Este es el caso del volcán Eyjafjallajökull, 
en Islandia, que en el año 2010 entró en erupción, emitiendo una gran columna de gas y ceniza y derritiendo parte de un glaciar. La nube de ceniza fue suficientemente significativa para cerrar los aeropuertos en más de 20 países europeos y suspender más de 100.000 vuelos. Se estima que supuso unas pérdidas de Producto Interior Bruto de 5000 millones de dólares (Oxford Economics 2015).

Por otra parte, no podemos olvidar los aspectos positivos del fenómeno volcánico para la Humanidad y que también se remontan a los albores de la historia, y que serán apuntados en el apartado 3.6.

Sin duda, una enseñanza de las ciencias, en este caso del fenómeno volcánico, que integre elementos de historia sería compatible con estrategias como CTS o el reciente movimiento STEAM (Perales y Aguilera 2020; Lewis 2015).

\section{Medios audiovisuales y TIC}

Existen multitud de recursos audiovisuales que abordan esta temática, sean para adultos o también para niños. Algunos ejemplos son ¿Cómo se forma un volcán? ${ }^{1}$ o Zamba. ¿Qué son los volcanes?2

Cabe reseñar que la utilización de vídeos de erupciones reales puede ayudar a rebatir ideas previas erróneas sobre el vulcanismo; por ejemplo, la relativa a la importancia de erupciones piroclásticas frente a las de lava y cómo las primeras son las que realmente plantean más riesgos, en conjunción con otros fenómenos desconocidos como son los lahares. En este sentido, son paradigmáticas las grabaciones de la erupción del volcán St Helen en $1980^{3}$. También lo es el flujo piroclástico que acabó con la vida del matrimonio de vulcanólogos Kraft en el volcán Unzen (Japón) en 1991y que quedó registrado en sus cámaras ${ }^{4}$.

\section{Cine}

Desde una de las primeras adaptaciones cinematográficas de la novela Los últimos días de Pompeya (1935) se ha sucedido un séquito de películas sobre esta temática incluyendo Krakatoa, Al este de Java (1969), La isla del fin del mundo (1974), Volcano (1997), Un pueblo llamado Dante's Peak (1997), Pompeya: el último día (2003), Supervolcano (2005, docudrama) o Súper Erupción (2011), entre otras (Aulinas-Juncà et al. 2015).

Otros ejemplos más recientes con formato documental son la Serie Documental Cómo funciona la Tierra (Dmax 2014) y Dentro del Volcán (Netflix 2016).

De cara a su uso educativo deberían separarse claramente las producciones que poseen una naturaleza meramente catastrofista-sensacionalista, normalmente de carácter comercial, de las que buscan informar y describir el fenómeno volcánico (Perales 2020).

\section{Literatura y arte}

Son múltiples las referencias desde la literatura a los volcanes ${ }^{5}$. Reproducimos a continuación un fragmento de la descripción de Curzio Malaparte (seudónimo utilizado por el escritor Kurt Erich Suckert) en su obra La piel sobre la erupción del Vesubio en el año 1944, testigo del mismo, coincidiendo con el desembarco y asentamiento de las tropas aliadas (Malaparte 1988):

«El cielo, a Oriente, desgarrado por una inmensa herida, sangraba y la sangre teñía de rojo el mar. El horizonte se resquebrajaba, hundiéndose en un abismo de fuego. Sacudida por

\footnotetext{
${ }^{1}$ https://www.youtube.com/watch?v $=$ ApCEe-mXV2U

2 https://youtu.be/h5CSN_fGHAw

3 https://youtu.be/AYla6q3is6w

${ }^{4}$ https://mujeresconciencia.com/2017/05/23/volcanes-volcanes-mas-volcanes-aventuras-peligrosas-katia-krafft/

${ }^{5}$ Por ejemplo, https://elcoloquiodelosperros.weebly.com/artiacuteculos/libros-y-volcanes-literatura-y-centroamerica
} 
profundas conmociones, la Tierra temblaba, las casas temblaban sobre sus cimientos, y ya se oía el ruido sordo de la caída de las tejas y las paredes que se derrumbaban desde lo alto de los tejados al pavimento de la calle, signo precursor de una universal ruina. Un estallido horrendo circuló por el aire, como de huesos triturados. Y sobre ese horrible estrépito, sobre los aullidos de terror del pueblo que corría de un lado para otro andando a tientas como un ciego, se alzaba, desgarrando el cielo, un terrible grito...» (p. 227).

Se entremezcla un lenguaje poético con otro descriptivo de la terrible destrucción provocada por la erupción, que venía a sumarse a las condiciones humanas de un país devastado por la II Guerra Mundial. Puede ser una buena oportunidad para relacionar las Ciencias de la Tierra con el lenguaje literario, pudiéndose contrastar con algunos documentos gráficos que se conservan del suceso ${ }^{6}$.

En cuanto a las artes plásticas también son numerosos los cuadros que lo incluyen en sus temas, desde el siglo XVI a la actualidad, destacando los más de 90 artistas que recopila Sigurdsson (2015). También el Vesubio y sus erupciones destacan como las más representadas.

\section{Riesgo}

Términos como riesgo o resiliencia han pasado a formar parte durante las últimas décadas del lenguaje educativo, y el tópico de los volcanes se presta especialmente a ello, dado su impacto socioambiental y la vulnerabilidad de las poblaciones aledañas. El primero hace referencia a la percepción de la población de las consecuencias negativas de una erupción, y el segundo a su capacidad de recuperación frente a las mismas. Dada la insuficiente gestión que de estas situaciones suelen hacer las autoridades, es prioritario fomentar estrategias de actuación por parte de los propios afectados (Boin y McConnell 2007). La actual crisis pandémica provocada por la Covid19 nos proporciona un escenario idóneo para contrastar esa necesidad.

No obstante, como señalan Carracedo y Pérez-Torrado (2015) el riesgo volcánico es hoy día inferior al de otras catástrofes naturales como los terremotos e inundaciones, ayudado sin duda por la mejora en las técnicas de detección temprana de las erupciones.

\section{Beneficios}

Como expresan Kelman y Mather (2008), la investigación ha prestado bastante más atención a las amenazas que a las oportunidades. Entre estas últimas podemos mencionar, entre otros, los recursos minerales, agrícolas (por el aporte de minerales al suelo), energéticos (energía geotérmica) o socioeconómicos (como el turismo).

Ciertamente las explotaciones geotermales que aportan fuente de calor, o producción de electricidad, no solo se desarrollan sobre terrenos volcánicos. Además, globalmente, la geotermia solo supone un $0,22 \%$ de la producción eléctrica mundial. Sin embargo, en algunos países puede ser muy importante, como en el caso de Kenia, y la tendencia de producción eléctrica relacionada con la superación de problemas técnicos está en alza (Arnórsson, Thórhallsson y Stefánsson 2015; Allahvirdizadeh 2020)

En el caso de los recursos minerales en la actualidad y soslayando su papel a lo largo de la historia $^{7}$, se podrían considerar los productos volcánicos como minerales industriales, lubricantes, abrasivos o de construcción. Además han podido emplearse con fines artísticos y otros usos locales (Dehn y McNutt 2015). Pero sobre todo, habría que mencionar que el vulcanismo juega un papel determinante por el aporte de metales, fluidos y/o calor en la formación de importantes yacimientos minerales de metales preciosos o metales base $(\mathrm{Cu}, \mathrm{Zn}$,

\footnotetext{
$\overline{6}$ https://www.youtube.com/watch?v $=A-P 6 q Q f c 5 f w$

${ }^{7}$ Por ejemplo, los romanos en la Antigüedad fabricaban su hormigón mezclando ceniza volcánica con cal y agua del mar. Así conseguían un mortero al que después incorporaban trozos de roca volcánica.
} 
$\mathrm{Pb} . .$.$) , como ocurre en una parte apreciable de los yacimientos hidrotermales o incluso en$ ciertos casos la propia roca volcánica contiene directamente la mena de interés, como es el diamante en las kimberlitas o las Tierras Raras en carbonatitas. Si consideramos no solo el vulcanismo, sino el magmatismo en su conjunto, una parte muy relevante de los recursos metálicos y las materias primas críticas, se asocia al mismo directa o indirectamente (Ridley 2013; Wang, Fan, Zhou, Yang y She 2020).

Finalmente, el turismo de volcanes, sean activos o extintos, constituye una fuente de ingresos para las comunidades locales y una forma de divulgar y apreciar este fenómeno natural entre los visitantes. Un ejemplo de dicha iniciativa es la del aventurero y vulcanólogo Thomas Pfeiffer que ha creado una singular agencia de viajes; él, junto con un equipo de expertos locales, programa viajes a los volcanes con mayor actividad del planeta ${ }^{8}$. A nivel institucional, los paisajes volcánicos son elementos sujetos de protección, así como de una explotación sostenible turística. En este sentido 58 de 1031 (5,8\%), 57 de 651 (8,7\%) y 21 de 120 (17,5\%) son sitios Patrimonio de la Humanidad, Reservas de la Biosfera y Geoparques Globales, respectivamente, que tienen una estrecha relación con el vulcanismo (Németh, Casadevall, Moufti y Marti 2017). En el caso español, con el surgimiento de la red de geoparques siguiendo la estela europea, cabe señalar que de los 15 que existen en la actualidad, el vulcanismo o sus productos juegan un papel central en tres de ellos $(20 \%)$. Por ejemplo, El Hierro fue declarado geoparque en septiembre de 2014 y Lanzarote y Archipiélago Chinijo en abril de 2015, todos ellos en las Islas Canarias.

\section{Consideraciones finales}

Creemos haber mostrado en estas páginas algunas de las implicaciones y oportunidades que posee la temática de los volcanes en el ámbito educativo.

Sin poder entrar en la complejidad y trayectoria del enfoque de Ciencia-Tecnología-Sociedad (CTS), dado que no es el propósito principal de este artículo, sí creemos que el fenómeno volcánico constituye un ejemplo paradigmático de aquel. Así, en la síntesis de sus características realiza por Acevedo, Vázquez y Manassero (2003), para el caso que nos ocupa podríamos seleccionar las siguientes a las que se ajusta el tema que nos hallamos abordando:

- La inclusión de la dimensión social en la educación científica, ya vista en el apartado correspondiente a esta denominación.

- La familiarización con los procedimientos de acceso a la información, su utilización y comunicación. En los ejemplos de intervenciones educativas y en la propia dimensión social hemos tenido la oportunidad de hallar cómo las TIC pueden contribuir a modelizar el fenómeno volcánico y acceder a la visualización de algunas de sus manifestaciones ante la imposibilidad del acceso real.

- El papel humanístico y cultural de la ciencia y la tecnología. Ello se ha visto reflejado en la perspectiva histórico-artística que hemos presentado dentro de la dimensión social.

- Su uso para propósitos específicos sociales y la acción cívica (p. 90). En esta característica se inscribirían los apartados de riesgo y beneficios de la actividad volcánica para la humanidad.

Otra implicación para la investigación educativa podría ser la elaboración de un modelo de volcán mediante una progresión en su complejidad que pudiera ser tomado como referencia para su enseñanza en Primaria y Secundaria.

\footnotetext{
$\overline{8 \text { https: / / www.youtube.com/watch?v }}=\mathrm{cIHPPjikmVs}$
} 
Para ello habría que revisar en profundidad las ideas previas de los estudiantes en ambas etapas educativas y establecer objetivos de aprendizaje realistas que no desbordasen las posibilidades cognitivas de aquellos, procurando que su simplicidad inicial no incurriese en errores conceptuales que posteriormente actuaran como obstáculos de aprendizaje. Las dimensiones que nos han servido de guía en este trabajo (Tabla 1) podrían orientarnos al respecto, por ejemplo, incidiendo en Primaria en las relativas a su ubicación, tipos de erupciones, riesgo y otros. Una vez consensuado ese modelo podría servir como contraste de los libros de texto y, en su caso, como orientación al profesorado sobre su abordaje.

\section{Agradecimientos}

Este artículo se inscribe en el Proyecto "Aplicación de técnicas de procesado de señales y de aprendizaje automático sobre señales sísmicas para pronosticar erupciones volcánicas", del Ministerio de Ciencia e Innovación (ref. PID2019-106260GB-I00) y del Grupo de Investigación de la Junta de Andalucía, en Didáctica de las Ciencias Experimentales y de la Sostenibilidad (ref. HUM 613).

\section{Referencias}

Acevedo J.A., Vázquez A., Manassero, M.A. (2003) Papel de la educación CTS en una alfabetización científica y tecnológica para todas las personas. Revista Electrónica de Enseñanza de las Ciencias, 2 (2), 80-111.

Allahvirdizadeh P. (2020) A review on geothermal wells: Well integrity issues. Journal of Cleaner Production, 275. https://doi.org/10.1016/j.jclepro.2020.124009

Arnórsson S., Thórhallsson S., Stefánsson A. (2015) Utilization of geothermal resources. En H. Sigurdsson (Ed.), The Encyclopedia of Volcanoes (pp. 1235-1252). New York: Academic Press.

Aulinas Juncà M., Rodriguez-González A., Planagumà Guàrdia L. (2015) Los volcanes en la red (www): la enciclopedia del siglo XXI. Enseñanza de las Ciencias de la Tierra, 23 (1), $107-120$

Blake A. (2005) Do young children's ideas about the Earth's structure and processes reveal underlying patterns of descriptive and causal understanding in earth science? Research in Science and Technological Education, 23 (1), 59-74.

Boin A., McConnell A. (2007) Preparing for critical infrastructure breakdowns: The limits of crisis management and the Need for Resilience. Journal of Contingencies and Crisis Management, 15, 50-59.

Boudreaux H., Bible P., Cruz-Neira C., Parham T., Cervato C., Gallus W., Stellinget P. (2009) V-Volcano: Addressing Students' Misconceptions in Earth Sciences Learning through Virtual Reality Simulations. En G. Bebis, R. Boyle, B. Parvin, D. Koracin, Y. Kuno, J. Wang, J.X. Wang, J. Wang, R. Pajarola, P. Lindstrom, A. Hinkenjann, M. L. Encarnação, C.T. Silva, D. Coming (Eds.), Advances in Visual Computing. ISVC 2009. Lecture Notes in Computer Science, vol 5875 (pp.1009-1018). Berlin, Heidelberg: Springer https://doi.org/10.1007/978-3-642-10331-5_94

Büntgen U., Myglan C.J., Wagner S., Krusic P.J., Esper J., Tegel W., Kirdyanov A.V. (2016) Cooling and societal change during the Late Antique Little Ice Age from 536 to around 660 AD. Nature Geoscience, 9 (3), 231-236. https://doi.org/10.1038/ngeo2652

Carracedo J.C., Perez-Torrado F.J. (2015) Peligros volcánicos ¿predecibles, prevenibles, mitigables?. Enseñanza de las Ciencias de la Tierra. 23 (1), 5-11. 
Carrillo-Rosúa J., Vílchez-González J.M., González-García F. (2010) Ideas previas en el alumunnado de magisterio de educación primaria sobre el interior de la tierra. II Congreso Internacional de Didácticas, Gerona, pp. 121-146.

Carrillo-Rosúa J., Vílchez-González J.M., Fernández-Oliveras A. (2014) El interior terrestre y el origen del magma visto por profesorado en formación de Educación Primaria y Secundaria: punto de partida para una propuesta basada en el uso de pruebas. En M.A. de las Heras (Ed.), Investigación y transferencia para una educación en ciencias: un reto emocionante (pp. 858-865). Huelva: APICE, Universidad de Huelva, Universidad Internacional de Andalucía.

Carrillo-Rosúa J., García-Yeguas A., Perales F.J., Vázquez M. (2021) ¿Qué es un volcán? Una aproximación a través del análisis de páginas web. Comunicación al XI Congreso Internacional sobre Investigación en Didáctica de las Ciencias (en prensa).

Dal B. (2006) The Origin and Extent of Student's Understandings: The Effect of Various Kinds of Factors in Conceptual Understanding in Volcanism. Electronic Journal of Science Education, 11 (1), 38-59.

Decreto 111/2016, de 14 de junio, por el que se establece la ordenación y el currículo de la Educación Secundaria Obligatoria en la Comunidad Autónoma de Andalucía (BOJA 28-06-2016).

Dehn J., McNutt S.R. (2015) Volcanic materials in commerce and industry. En H. Sigurdsson (Ed.), The Encyclopedia of Volcanoes (pp. 1285-1294). New York: Academic Press.

Dörries M. (2003) Global science: The eruption of Krakatau. Endeavour, 27 (3), 113-116). https://doi.org/10.1016/S0160-9327(03)00107-8

Eddif E., Selmaoui S., Chakour R. (2018) Images of Moroccan Geological Heritage in Life and Earth Sciences Textbooks of Second Year College from 2004 to 2017: Case of the Volcanic Chain of the Middle Atlas. Journal of Education, Society and Behavioural Science, 28 (2), 1-11. https://doi.org/10.9734/JESBS/2018/45256

Ejarque Ortiz A., Bravo Torija B., Mazas Gil, B. (2016) Diseño e implementación de una actividad de modelización de geología: ¿realmente la corteza es tan gruesa y los volcanes tan profundos? Revista Internacional de Investigación e Innovación en Didáctica de las Humanidades y las Ciencias, 3, 9-32.

Fernández Oliveras A., Vílchez-González J.M., Carrillo-Rosúa J. (2016) ¿De dónde procede el magma que expulsan los volcanes? Experiencia piloto de una propuesta basada en el uso de pruebas para la formación inicial del profesorado de Educación Primaria. En J.L. Bravo Galán (Ed.), Libro de actas de los 26 Encuentros de Didáctica de las Ciencias Experimentales (pp. 1205-1212). Badajoz: Universidad de Extremadura y APICE.

Francek M. (2013) A Compilation and Review of over 500 Geoscience Misconceptions. International Journal of Science Education, 35 (1), 31-64.

García-Yeguas A., Vílchez J.M. (2021) La atención prestada al fenómeno volcánico en la investigación educativa. Revisión sistemática. 29 Encuentros de Didáctica de las Ciencias Experimentales. Córdoba, 1-7.

Harpp K.S., Koleszar A.M., Geist D.J. (2005) Volcanoes in the classroom: A simulation of an eruption column. Journal of Geoscience Education, 53 (2), 173-175. https://doi.org/10.5408/1089-9995-53.2.173 
Kelman I., Mather T.A. (2008) Living with volcanoes: The sustainable livelihoods approach for volcano-related opportunities. Journal of Volcanology and Geothermal Research, 172, 189-198.

Kim G., Yang H.R., Kang K.K., Kim D. (2010) Entertaining Education: User Friendly Cutting Interface for Digital Textbooks. 9th International Conference on Entertainment Computing (ICEC). Seoul, 405-41.

King C. (2008) Geoscience education: an overview. Studies in Science Education, 44 (2), 187-222.

King C. (2010) An Analysis of Misconceptions in Science Textbooks: Earth science in England and Wales. International Journal of Science Education, 32 (5), 565-601. https://doi.org/10.1080/09500690902721681

Lee, H., Bae, S. (2008) Issues in Implementing a Structured Problem-based Learning Strategy in a Volcano Unit: A Case Study. International Journal of Science and Mathematics Education, 6, 655-676.

Lewis A. L. (2015) Putting the " $H$ " in STEAM: Paradigms for modern liberal arts education. En: X. Ge, D. Ifenthaler, J. M. Spector (Eds.), Emerging Technologies for STEAM Education (pp. 259-275). Heidelberb: Springer.

Malaparte C. (1988) La piel. Barcelona: Ed. Orbis.

Martí J., Folch, A. (1999) El porqué de los volcanes. Enseñanz̧a de las Ciencias de la Tierra, 7 (3), 194-199.

Miller C.F., Wark D.A. (2008) Supervolcanoes and their explosive supereruptions. Elements, 4 (1), 11-15. https://doi.org/10.2113/GSELEMENTS.4.1.11

Németh K., Casadevall T., Moufti M.R., Marti J. (2017) Volcanic Geoheritage. Geoheritage, 9 (3), 251-254. https://doi.org/10.1007/s12371-017-0257-9

Onida M., Segalini L (2006) Investigación didáctica en la escuela primaria: una experiencia sobre los fenómenos volcánicos. Enseñanz̧a de las Ciencias de la Tierra, 14 (3), 247-258.

Oxford Economics (2015) The economics of air travel restrictions due to volcanic ash. Prepared for AirBus Industries. https://www.oxfordeconomics.com/my-oxford/projects/129051

Parham T.L., Cervato C., Gallus W.A., Larsen M., Hobbs J.M, Stelling P., Gupta T., Knox J.A., Gill T.E. (2010) The InVEST Volcanic Concept Survey: Exploring Student Understanding About Volcanoes. Journal of Geoscience Education, 58 (3), 177-187.

Perales F.J. (2020) Educación Ambiental y medios de comunicación: revisión de la literatura y propuestas de intervención. Revista de Educación Ambiental y Sostenibilidad, 2 (2), 1-17. http://dx.doi.org/10.25267/Rev_educ_ambient_sostenibilidad.2020.v2.i2.2102

Perales F.J., Aguilera Morales D. (2020) Ciencia-Tecnología-Sociedad vs. STEM: ¿evolución, revolución o disyunción? Apice. Revista de Educación Científica, 4 (1), 1-15.

Putirka K. D. (2017) Down the crater: Where magmas are stored and why they Erupt. Elements, 13 (1), 11-16. https://doi.org/10.2113/gselements.13.1.11

Pujadas A., Brusi D., Pedrinaci E. (1999) ¡Los volcanes han cambiado! Nuevos enfoques de terminología volcánica. Enseñanza de las Ciencias de la Tierra, 7 (3), 200-209.

Real Decreto 126/2014, de 28 de febrero, por el que se establece el currículo básico de la Educación Primaria (BOE 01-03-2014). 
Real Decreto 1105/2014, de 26 de diciembre, por el que se establece el currículo básico de la Educación Secundaria Obligatoria y del Bachillerato (BOE 03-01-2015).

Ridley J. (2013) Ore deposit geology. Cambridge: University Press.

Self S., Blake S. (2008) Consequences of explosive supereruptions. Elements, 4 (1), 41-46. https://doi.org/10.2113/GSELEMENTS.4.1.41

Sigurdsson H. (2015) Volcanoes in art. En H. Sigurdsson (Ed.), The encyclopedia of volcanoes, $2^{\circ}$ edition (pp. 1321-1343). New York: Academic Press.

Sigurdsson H., Bruce F. H., Stephen R.M., John S., Haxel R. (2000) Encyclopedia of Volcanoes. New York: Academic Press.

Vergara-Díaz C, Bustamante K., Pinto L., Cofré H. (2020) Exploring Chilean seventh grade students'conceptions of Earth dynamics before and after model- and inquiry-based instruction. Journal of Geosciences Education, 68 (4), 360-370.

Vílchez-González J.M., Prudencio J., Urbano-Rodríguez L., Ibáñez J.M., Carrillo-Rosúa F.J. (2014) El conocimiento sobre volcanes en Educación Primaria. En J.J. Maquilón Sánchez, A. Escarbajal Frutos, R. Nortes Martínez-Artero (Eds.), Vivencias innovadoras en las aulas de Primaria (pp. 464-477). Universidad de Murcia, Servicio de Publicaciones

Wang Z.-Y., Fan H.-R., Zhou L., Yang K.-F., She H.-D. (2020) Carbonatite-related REE deposits: An overview. Minerals, 10 (11), 1-26. https://doi.org/10.3390/min10110965 
Anexo 1. Revisión bibliográfica sobre ideas previas de los estudiantes.

\begin{tabular}{|c|c|c|c|}
\hline Autores & Muestra & Técnicas de diagnóstico & Principales resultados \\
\hline $\begin{array}{l}\text { Blake } \\
(2005)\end{array}$ & $\begin{array}{l}115 \text { niños de } \\
7 \text { a } 11 \text { años, } \\
\text { de distintas } \\
\text { capacidades y } \\
\text { género de una } \\
\text { escuela } \\
\text { primaria no } \\
\text { selectiva } \\
\text { marginal en el } \\
\text { centro de la } \\
\text { ciudad }\end{array}$ & $\begin{array}{l}\text { Etapa 1: (Dibujos previos a } \\
\text { la entrevista y cuestionario } \\
\text { de proceso). } \\
\text { Etapa 2: (Practical Rock } \\
\text { Task [PRT]). } \\
\text { Etapa 3: (Entrevistas } \\
\text { seleccionadas). } \\
\text { Criterios de evaluación: } \\
\text { Nivel 1: no científico } \\
\text { Nivel 2: Proto-científico } \\
\text { Nivel 3: Científico } \\
\text { A los niños que no } \\
\text { reconocieron los volcanes } \\
\text { como eventos naturales se } \\
\text { les otorgó el Nivel } 1 . \text { A los } \\
\text { niños que sí reconocieron } \\
\text { los volcanes como eventos } \\
\text { naturales, pero dijeron que } \\
\text { no ocurrieron en el pasado, } \\
\text { se les otorgó el Nivel } 2 \text {, } \\
\text { mientras que los que } \\
\text { creyeron que habían } \\
\text { ocurrido tanto en el pasado } \\
\text { como el presente se } \\
\text { asignaron al Nivel } 3 \text {. }\end{array}$ & $\begin{array}{l}\text { Con respecto a la causalidad, el Nivel } 1 \text { se } \\
\text { asignó a los niños que no sabían qué causó las } \\
\text { erupciones volcánicas (sucedió solo) u ofrecieron } \\
\text { alguna causa humana, por ejemplo, ruidos } \\
\text { fuertes o personas caminando sobre el suelo } \\
\text { provocando vibraciones. Las causas del nivel } 2 \\
\text { fueron naturalistas, pero excéntricas (por } \\
\text { ejemplo, el volcán se llena demasiado de lava) o } \\
\text { se acercaron a cierto grado de conocimiento } \\
\text { científico (por ejemplo, calor interno del núcleo } \\
\text { o magma forzado por la presión del gas debajo } \\
\text { de la Tierra). Las respuestas de nivel } 3 \\
\text { relacionaron la actividad volcánica con la acción } \\
\text { de las placas de la corteza. Todos los niños } \\
\text { entrevistados demostraron un nivel } \\
\text { protocientífico de comprensión con respecto a } \\
\text { los volcanes. }\end{array}$ \\
\hline Dal (2006) & $\begin{array}{l}130 \\
\text { estudiantes de } \\
\text { una escuela } \\
\text { primaria (año } \\
6 \text { ), una } \\
\text { escuela } \\
\text { secundaria } \\
\text { (año 9) y } \\
\text { estudiantes de } \\
\text { maestros }\end{array}$ & $\begin{array}{l}\text { Recogida de información } \\
\text { mediante la asociación de } \\
\text { ideas, una prueba Q-Sort y } \\
\text { un cuestionario con } \\
\text { preguntas abiertas }\end{array}$ & $\begin{array}{l}\text { Las categorías definidas son las siguientes: } \\
\text { Tipo 1: un cono volcánico sin detalle } \\
\text { estructural, con respuestas diversas y poco } \\
\text { claras sobre el origen de la lava, incluso la } \\
\text { ausencia de respuesta; sin mención de escalas de } \\
\text { tiempo (16\%) } \\
\text { Tipo 2: cono bien demarcado, con estructura } \\
\text { interna; los estudiantes que realizan este tipo de } \\
\text { dibujo dan a la lava un origen superficial } \\
\text { relacionado con el volcán (interior del volcán, en la } \\
\text { cima del volcán); sin mención de escalas de tiempo } \\
\text { y mención específica de escalas de tiempo } \\
\text { cortas (años o menos) (36\%) } \\
\text { Tipo 3: un cono lleno de lava, asociado a un } \\
\text { origen mayor (pero vago) que incluye la lava está } \\
\text { bajo tierra y sube para llenar el volcán; mención } \\
\text { específica de escalas de tiempo cortas (años o } \\
\text { menos) } \\
\text { Tipo 4: presencia de un pozo que une la } \\
\text { estructura volcánica con un reservorio, punto } \\
\text { profundo de origen de la lava; mención } \\
\text { específica de escalas de tiempo cortas (años o } \\
\text { menos) y términos generales de tiempo } \\
\text { utilizado (36\%) (muchos años). } \\
\text { Tipo 5: una estructura con un eje sin terminar; } \\
\text { punto profundo de origen de lava; mención } \\
\text { específica de escalas de tiempo cortas y } \\
\text { términos generales de tiempo utilizados } \\
\text { (muchos años). } \\
\text { Tipo 6: un eje que une el volcán con una capa o }\end{array}$ \\
\hline
\end{tabular}




\begin{tabular}{|c|c|c|c|}
\hline & & & $\begin{array}{l}\text { capa de lava; origen profundo, pero que a } \\
\text { menudo evoca la corteza terrestre, el sótano y las } \\
\text { capas internas de la Tierra; términos generales de } \\
\text { tiempo utilizado (muchos años), mención } \\
\text { específica de escalas de tiempo medio (mil) } \\
(9 \% \text { y mención específica de escalas de tiempo } \\
\text { largas (millones) ( } 3 \% \text { ). } \\
\text { Tipo 7: estructura volcánica compuesta por dos } \\
\text { placas terrestres que chocan; origen profundo de } \\
\text { la lava; mención específica de escalas de tiempo } \\
\text { largas (millones). } \\
\text { Tanto los estudiantes como los futuros } \\
\text { profesores tenían concepciones alternativas } \\
\text { sorprendentemente similares a pesar de que } \\
\text { estos últimos recibieron más instrucción sobre } \\
\text { este tema. Además, a lo largo del currículo, se } \\
\text { hizo evidente una relación más estrecha entre } \\
\text { las concepciones alternativas y el conocimiento } \\
\text { científico aceptado. Por tanto, fue posible trazar } \\
\text { un mapa de las categorías de concepciones } \\
\text { alternativas del vulcanismo y medir la influencia } \\
\text { del currículo observando la evolución de estas } \\
\text { concepciones alternativas. }\end{array}$ \\
\hline $\begin{array}{l}\text { King } \\
(2008)\end{array}$ & $\begin{array}{l}\text { Revisión } \\
\text { bibliografía }\end{array}$ & Revisión bibliografía & $\begin{array}{l}\text { Los procesos ígneos implican la fusión y } \\
\text { posterior solidificación de la roca. Dove (1998) } \\
\text { revisó el trabajo sobre conceptos erróneos de } \\
\text { procesos lejanos, y encontró confusión entre } \\
\text { erupciones volcánicas y terremotos. Libarkin y } \\
\text { col. (2005) mostró que los estudiantes } \\
\text { universitarios de los EE. UU. «Creían que los } \\
\text { volcanes solo ocurren en islas, que están } \\
\text { asociados con climas cálidos y que los volcanes } \\
\text { solo ocurren a lo largo del ecuador» (p. 24) y } \\
\text { Marques (1988) informó hallazgos similares } \\
\text { para estudiantes portugueses de } 10 \text { a } 15 \text { años. } \\
\text { Lillo (1994) y Dahl et al. (2005) identificaron el } \\
\text { malentendido de que el magma que entra en } \\
\text { erupción a través de los volcanes se origina en } \\
\text { el núcleo de la Tierra, cuando se cree que } \\
\text { prácticamente todo el magma se origina en la } \\
\text { parte superior del manto o la corteza. Este } \\
\text { trabajo muestra que muchos alumnos no } \\
\text { relacionan los volcanes con los procesos que los } \\
\text { forman. }\end{array}$ \\
\hline $\begin{array}{l}\text { Boudre- } \\
\text { aux et al. } \\
(2009)\end{array}$ & ¿? & $\begin{array}{l}\text { Programa de realidad } \\
\text { virtual }\end{array}$ & $\begin{array}{l}\text { Se identificaron los siguientes cuatro conceptos } \\
\text { erróneos principales sobre la formación } \\
\text { volcánica: } \\
\text { 1. Los volcanes solo se forman cerca de cuerpos } \\
\text { de agua } \\
\text { 2. Los volcanes son comunes solo en áreas } \\
\text { cercanas al ecuador u otras áreas cálidas } \\
\text { 3. Aparecen volcanes en zonas de terreno } \\
\text { rocoso } \\
\text { 4. No existe un patrón de formación de } \\
\text { volcanes } \\
\text { Además, varios conceptos se entendieron muy } \\
\text { mal. Estos incluyen el funcionamiento interno }\end{array}$ \\
\hline
\end{tabular}




\begin{tabular}{|c|c|c|c|}
\hline & & & $\begin{array}{l}\text { de un volcán, lo que controla la actividad } \\
\text { explosiva, el papel de la sílice en la actividad } \\
\text { explosiva y los efectos de la actividad volcánica } \\
\text { en el medio ambiente circundante y la } \\
\text { civilización humana. }\end{array}$ \\
\hline $\begin{array}{l}\text { Parham T. } \\
\text { L., Cervato } \\
\text { C., Gallus } \\
\text { W. A., } \\
\text { Larsen M., } \\
\text { Hobbs } \\
\text { J.M, } \\
\text { Stelling P., } \\
\text { Gupta T., } \\
\text { Knox J. A., } \\
\text { Gill T. E. } \\
\text { (2010) }\end{array}$ & $\begin{array}{l}672 \\
\text { posgraduados }\end{array}$ & $\begin{array}{l}\text { Encuesta de conceptos } \\
\text { volcánicos }\end{array}$ & $\begin{array}{l}\text { Las preguntas que solo requieren conocimientos } \\
\text { básicos de contenido (p. ej., terminología, } \\
\text { topología volcánica) recibieron respuestas de } \\
\text { mayor puntuación que las preguntas que } \\
\text { requieren un pensamiento más elevado y } \\
\text { conexiones conceptuales más profundas } \\
\text { (asociación con la tectónica de placas, } \\
\text { predicción de peligros e impactos en el medio } \\
\text { ambiente). La mecánica de las erupciones } \\
\text { también parecía ser poco conocida. Se prestó } \\
\text { especial atención a las concepciones alternativas } \\
\text { de los estudiantes sobre dónde es probable que } \\
\text { se formen los volcanes. Los estudiantes varones, } \\
\text { los estudiantes muy interesados en la ciencia y } \\
\text { los estudiantes que vivían en un área } \\
\text { volcánicamente activa recibieron puntajes } \\
\text { totales significativamente más altos que otros } \\
\text { grupos de estudiantes. Las especialidades de } \\
\text { ciencia, tecnología, ingeniería y matemáticas } \\
\text { (STEM) también se desempeñaron } \\
\text { significativamente mejor que las especialidades } \\
\text { que no son de STEM. }\end{array}$ \\
\hline $\begin{array}{l}\text { Carrillo, J., } \\
\text { Vílchez, } \\
\text { J.M. y } \\
\text { Fernández, } \\
\text { A. (2010) }\end{array}$ & $\begin{array}{l}57 \text { maestros } \\
\text { en formación }\end{array}$ & $\begin{array}{l}\text { Dibujo de un corte } \\
\text { esquemático de la Tierra, } \\
\text { en el que se localizara el } \\
\text { magma que genera las } \\
\text { rocas ígneas en relación } \\
\text { con la estructura interna de } \\
\text { la Tierra }\end{array}$ & $\begin{array}{l}\text { La mayor parte de los encuestados reconoce } \\
\text { que la Tierra se encuentra estructurada en } \\
\text { diferentes capas o niveles, a modo de una cebolla; } \\
\text { aunque solo el } 27 \% \text { identifica por completo la } \\
\text { división básica en } 3 \text { capas. } \\
\text { Solo un } 7 \% \text { de los esquemas realizados muestra } \\
\text { un tamaño razonable del espesor relativo entre } \\
\text { las distintas capas, siendo un error generalizado } \\
\text { la sobredimensión del espesor de la Corteza } \\
\text { terrestre. } \\
\text { Un porcentaje muy elevado, el } 81 \% \text {, localiza } \\
\text { erróneamente el magma en el Núcleo terrestre. } \\
\text { Cuando lo localizan en el Manto terrestre } \\
\text { (38\%), en general tampoco lo hacen } \\
\text { adecuadamente, ya que lo señalan } \\
\text { simultáneamente en el Núcleo y/o lo } \\
\text { representan como una capa continua en dicho } \\
\text { Manto. Cabe señalar también que en algunos } \\
\text { casos indican que el magma proviene solo del } \\
\text { Núcleo externo, conectando con la idea } \\
\text { acertada de que el Núcleo externo está en } \\
\text { estado líquido, aunque no sea el lugar de donde } \\
\text { procede el magma. } \\
\text { El porcentaje de magma que forma el interior } \\
\text { terrestre en estos esquemas es siempre muy } \\
\text { elevado, incluso en muchos de ellos mayoritario } \\
\text { respecto al total del volumen del planeta. En } \\
\text { relación con esta idea generalizada, se concibe el } \\
\text { magma formando una capa en el interior } \\
\text { terrestre, y solo en dos de los esquemas }\end{array}$ \\
\hline
\end{tabular}




\begin{tabular}{|c|c|c|c|}
\hline & & & $\begin{array}{l}\text { presentados se apunta hacia una localización } \\
\text { discreta, aunque no conectada con la tectónica } \\
\text { de placas. } \\
\text { Ninguno de los esquemas realizados es } \\
\text { satisfactorio en relación con el lugar de la Tierra } \\
\text { donde se genera el magma y su relación con las } \\
\text { placas tectónicas y su dinámica. Bien es cierto } \\
\text { que el alumnado, en su mayoría, no ha realizado } \\
\text { estudios científicos en Educación Secundaria, y } \\
\text { es posible que no haya recibido enseñanzas } \\
\text { sobre tectónica de placas, o de otras temáticas } \\
\text { geológicas. A este déficit puede contribuir el } \\
\text { perfil profesional de la mayor parte del } \\
\text { profesorado de Ciencias de la Naturaleza de } \\
\text { Secundaria y la extensión del programa a } \\
\text { impartir, siendo notable la falta de tiempo para } \\
\text { desarrollarlo en su totalidad. } \\
\text { Aunque no se pedía específicamente, ningún } \\
\text { esquema hacía referencia a las rocas plutónicas } \\
\text { (aunque ya se habían tratado en clase las } \\
\text { distintas tipologías de roca), y sí al vulcanismo. } \\
\text { Aunque no se solicitaba la composición de las } \\
\text { distintas capas de la Tierra, se hace referencia a } \\
\text { ella en tres casos (uno totalmente incorrecto y } \\
\text { otros dos en los que se indicaba que el Núcleo } \\
\text { está formado por hierro). }\end{array}$ \\
\hline $\begin{array}{l}\text { Francek } \\
(2013)\end{array}$ & $\begin{array}{l}\text { Revisión } \\
\text { bibliografía }\end{array}$ & $\begin{array}{l}\text { Se utilizaron ocho } \\
\text { categorías de edad / grupo } \\
\text { para organizar la lista de } \\
\text { conceptos } \quad \text { erróneos: } \\
\text { primaria: K-grado } 5 \\
\text { (edades 5-10); escuela } \\
\text { intermedia: grados } 6 \text { a } 8 \\
\text { (de } 11 \text { a } 13 \text { años); escuela } \\
\text { secundaria: grados 9-12 } \\
\text { (14-17 años); } 6^{\circ} \text { a } 12^{\circ} \\
\text { grado de secundaria y } \\
\text { preparatoria; universidad } \\
\text { (17 años o más); profesores } \\
\text { en formación; profesores } \\
\text { en servicio e indefinidos }\end{array}$ & $\begin{array}{l}\text { Un error persistente era que los volcanes se } \\
\text { encontraban principalmente en climas cálidos } \\
\text { en ambientes terrestres, excluyendo los muchos } \\
\text { volcanes que se encuentran en zonas templadas } \\
\text { o frías, así como los volcanes que se encuentran } \\
\text { en el fondo del océano. Se pensaba que el } \\
\text { magma que suministraba la lava a los volcanes } \\
\text { se originaba en las profundidades del núcleo de } \\
\text { la tierra en oposición al manto superior. Al igual } \\
\text { que con los conceptos erróneos del suelo, hubo } \\
\text { poca investigación de conceptos erróneos a } \\
\text { nivel de escuela media y secundaria dedicada } \\
\text { solo a la morfología de los volcanes. Con } \\
\text { respecto a la forma y el estilo de erupción, } \\
\text { muchos grupos creían que todas las erupciones } \\
\text { volcánicas eran violentas y estaban } \\
\text { acompañadas de lava. Estudiantes universitarios } \\
\text { no estaban familiarizados con los peligros } \\
\text { secundarios como la principal causa de muerte y } \\
\text { lesiones por erupciones volcánicas y parece } \\
\text { justo que los estudios futuros también } \\
\text { encontrarán que este es el caso en el nivel K-12. }\end{array}$ \\
\hline $\begin{array}{l}\text { Vergara- } \\
\text { Diaz et al } \\
(2020)\end{array}$ & $\begin{array}{l}\text { Estudiantes } \\
\text { de } 1^{\circ} \mathrm{ESO}\end{array}$ & $\begin{array}{l}\text { Diseño cuasi-experimental, } \\
\text { con grupo control y } \\
\text { análisis pre y postest }\end{array}$ & $\begin{array}{l}\text { - Los volcanes son creados por el } \\
\text { calentamiento global } \\
\text { - Los volcanes son creados por el hombre } \\
\text { - Los volcanes son creados por impactos de } \\
\text { meteoritos. } \\
\text { - Los volcanes están formados por } \\
\text { deslizamientos de tierra }\end{array}$ \\
\hline
\end{tabular}

